RESEARCH ETHICS

\title{
Potential research participants' views regarding researcher and institutional financial conflicts of interest
}

\author{
S Y H Kim, R W Millard, P Nisbet, C Cox, E D Caine
}

J Med Ethics 2004;30:73-79

See end of article for authors' affiliations

\section{Correspondence to:}

Scott Y Kim, MD, PhD,

Department of Psychiatry,
300 Crittenden Boulevard

Rochester, NY 14642,

USA; Scott_Kim@

urmc.rochester.edu

Revised version received 28 August 2002

Accepted for publication

7 November 2002
Background: Financial conflict of interest in clinical research is an area of active debate. While data exist on the perspectives and roles of academic institutions, investigators, industry sponsors, and scientific journals, little is known about the perspectives of potential research participants.

Methods: The authors surveyed potential research participants over the internet, using the Harris Interactive Chronic Illness Database. A potential research participant was defined by: (1) self report of diagnosis by a health care professional and (2) willingness to participate in clinical trials. Email invitations were sent to 20205 persons with coronary artery disease, breast cancer, or depression; a total of 6363 persons were screened; of these, $86 \%$ or 5478 met inclusion criteria and completed the survey. The outcome measures were respondents' ratings on: importance of knowing conflict of interest information, whether its disclosure ought to be required, and its effect on willingness to participate-across seven widely discussed scenarios of financial conflicts of interest (ranging from commercial funding to equity ownership).

Results: Majority responded that knowing conflict of interest information was "extremely" or "very" important; a larger majority felt financial conflicts of interest should be disclosed as part of informed consent (64\% to $87 \%)$. In all seven scenarios, a majority was still willing to participate but in some scenarios a sizable minority would be wary of participation. Respondents were more wary of individual than institutional conflicts of interest. Illness group and sociodemographic factors had modest effects and did not affect the main trends.

Conclusions: The prevailing practice of non-disclosure of financial conflicts of interest in clinical research appears contrary to the values of potential research participants.
C linical research depends on patient volunteers serving as research subjects. Since benefit from participation is uncertain, patients must rely on the trustworthiness of the investigators who recruit them to help them decide whether to enrol in a study. ${ }^{1}$ An investigator's (or an institution's) financial conflicts of interest in clinical research have the potential to undermine this trust. ${ }^{2}$ Whereas the recently revised Declaration of Helsinki explicitly requires disclosure of sources of funding to the research subjects, ${ }^{3}$ there are no federal requirements on investigators or their institutions to disclose financial conflicts of interest to potential research participants. ${ }^{4}$ Only $1 \%$ of research institutions receiving greater than $\$ 5$ million in federal research funding have a policy requiring disclosure of conflict of interest to research subjects. ${ }^{4}$

There are several stakeholders in the conflict of interest debate: the researchers, ${ }^{5}{ }^{6}$ funding agencies, ${ }^{7}$ journals and their readers, ${ }^{8-10}$ academic medical centres, ${ }^{11-15}$ industry, ${ }^{16}$ and patients who form the pool of potential research participants. ${ }^{17}{ }^{18}$ Among these, the potential research participants have had the least input into the debate and virtually no data exist that examine their perspective. We surveyed potential research participants' views on seven widely discussed financial conflicts of interest situations. Among other questions, we asked two questions with important policy implications: Should financial conflict of interest information be required as part of informed consent? What proportion of the respondents say they would, solely based on the conflict of interest information, decline to participate?

\section{METHODS}

\section{Study subjects}

A potential research participant was, for the purposes of this study, defined by two criteria: (1) a person who reports that he or she has been diagnosed by a health care professional to have a major chronic illness; (2) a person who at the time of the survey affirms that he or she is willing to enrol in a clinical trial for a new treatment for his or her illness.

At the time of the survey (4-16 October 2000), Harris Interactive, a well known international polling firm, had a preregistered panel of 751622 persons in their Chronic Illness Database who had been recruited through internet web portal banner advertisements: all had self reported that they had been diagnosed with a chronic illness by a health care professional and had, prior to this survey, consented to be contacted for online surveys and for possible recruitment into clinical trials. This Chronic Illness Database catalogues patients with 45 different medical conditions. It has been used for recruitment of patients into clinical trials (unpublished data, HarrisInteractive files). Three highly prevalent illnesses-coronary artery disease, breast cancer, and depression-with varying psychosocial and medical consequences were chosen to assess the external validity of the survey.

This study was exempted from IRB review by the University of Rochester Research Subjects Review Board in accordance with Federal guidelines (45 CFR 46.101).

\section{Data collection}

A computer generated random sample of people 18 or older from each illness database category was sent an electronic mail message inviting them to complete an online survey on "How should research be funded?" A total of 20205 electronic invitations were sent (8829 heart disease, 3126 breast cancer, 8250 depression), containing a URL link to the survey web site and a unique password allowing access to the survey. The password helped assure that no one responded more than once and that only those targeted responded to the survey. A total of 6363 responded to the electronic invitation 
and were screened. Of these, 5478 or $86 \%$ stated their willingness to participate in a clinical trial at the time of the survey and were asked to complete the full survey. A sweepstakes incentive was used so that three respondents won $\$ 500$ each for completing the survey.

\section{Survey instrument}

By sending large numbers of email invitations, it was possible for thousands of respondents to simultaneously complete the survey online. Advanced survey techniques were used to adapt the survey instrument to the online environment, including password protection, programmed skip patterns, visually appealing fonts and formatting, random rotations of questions, range checks, and consistency checks. These checks were employed as the data were tabulated.

The instrument did not mention the phrase "conflict of interest" although seven conflict of interest scenarios were presented. All the scenarios considered a new drug for treatment of the respective illnesses of the respondents. The conflict of interest scenarios used were those widely discussed in the literature: commercial funding of clinical trials, ${ }^{19}$ personal income earned by investigators from the manufacturer of the new medication being tested, ${ }^{7}$ per capita enrolment payment to investigators, ${ }^{20} 21$ investigator and university ownership of patents for the medication being tested, ${ }^{1122-24}$ and investigator or university ownership of stocks in the company whose product is being tested..$^{2} 61125$

The seven scenarios were presented in random order to the respondents. Each respondent answered only from the perspective of his or her own self reported chronic illness. The scenario descriptions and the questions used are given in tables 1 and 2.

The four survey questions fell into two domains: the value placed on knowing the conflict of interest information (importance question and informed consent requirement question) and the reactions to such information (inclination question and behaviour question). While the two questions in each domain are similar, we were interested in both a general question for each domain as well as obtaining responses to specific questions of policy interest.

The inclination and behaviour questions were each followed up with an open ended invitation to comment on their answers. A qualitative analysis of these responses is underway; selected responses are included below, for illustrative purposes.

The survey questions were reviewed by experts (an IRB executive director, a senior medical centre official responsible for human subjects' research integrity, and a bioethicist with experience in drafting conflict of interest policies for a major medical association) and pretested with 10 lay persons in print form. The electronic version was pretested and revised by three of the authors (SYHK, PN, and RM) in collaboration with survey quality assurance team at Harris Interactive Inc.

\section{Data analysis}

Since the survey questions involved ordered, categorical responses, the effects of scenario and illness group on responses were analysed using a two way repeated measures analysis of variance modified for ordinal data. ${ }^{27}$ Illness group was the between subjects factor and scenario was a within subjects factor. Each analysis of variance was run both with and without interactions; if the test for interaction was negative, the model without the interaction was used. Pairwise comparisons of scenario effects on the responses for each survey question were performed using a two tailed significance level of 0.01 chosen to account for multiple comparisons. For the informed consent requirement question, because no interaction occurred between scenario and illness, pair-wise scenario effect comparisons were not done separately for each illness group but with responses of all three groups combined. For each of the four survey questions, the seven scenarios were ranked according to their effects, for each illness group (again, except for the informed consent requirement question). By the convention used in this paper, higher rank of a scenario means that, in comparison with the other scenarios, it tended to elicit responses of: greater likelihood of attributing higher importance, greater likelihood of requiring informed consent, greater likelihood of being disinclined to participate, and greater likelihood of saying one would not participate based on the conflict of interest information. Finally, a simple average rank score for each scenario, as an estimate of its overall effect on the responses by those surveyed, was also calculated.

The influence of demographic variables of sex, age, education, income, race/ethnicity, as well as of illness category on the responses of our subjects were analysed using multinomial logistic regression, ${ }^{28}$ using the levels indicated in table 3.

\section{RESULTS}

The characteristics of the survey completers and of those in the Chronic Illness Database for each illness group are described in table 3.

Table 1 Seven scenarios of financial conflicts of interest in clinical research

\begin{tabular}{|c|c|}
\hline Conflict type label & Scenario description \\
\hline Commercial funding & $\begin{array}{l}\text { Imagine that even though the study will be done at a university medical centre, the company that makes the new drug is paying for the } \\
\text { study. }\end{array}$ \\
\hline Personal income & $\begin{array}{l}\text { Imagine that the researcher conducting this study receives personal income from the study drug's manufacturer, from activities such as } \\
\text { consulting, being on advisory boards, and giving lectures at company sponsored events. }\end{array}$ \\
\hline Per capita payments & $\begin{array}{l}\text { Imagine that the drug company pays the researcher a lump sum of money per patient enrolled in the study that is greater than the } \\
\text { expenses required to conduct the study. The money left after expenses goes into the researcher's budget and is used in a variety of } \\
\text { ways - for example, for other research projects, for travel to meetings, and for support staff, etc. at the discretion of the researcher. }\end{array}$ \\
\hline Researcher patent & $\begin{array}{l}\text { Suppose the researcher owns the patent on the drug being studied. If this drug is found to be safe and effective for treating } \\
\text { [respondent's illness], the researcher would receive a part of the profits from the sales of the drug. }\end{array}$ \\
\hline University patent & $\begin{array}{l}\text { Suppose the university medical centre owns the patent on the drug. If it is found to be safe and effective in treating [respondent's } \\
\text { illness], the university would receive a part of the profits from the sales of the drug. }\end{array}$ \\
\hline Researcher stocks & $\begin{array}{l}\text { Suppose the new drug is made by a small biotechnology company. The researcher owns a substantial portion of the stocks of the } \\
\text { company. The value of the company's stocks can rapidly go up or down by large amounts depending on whether the drug is seen to } \\
\text { be safe and effective for treating [respondent's illness]. }\end{array}$ \\
\hline University stocks & $\begin{array}{l}\text { Suppose the drug is made by a small biotechnology company. The university medical centre owns substantial portion of the stocks of } \\
\text { the company. The value of the company's stocks can rapidly go up or down by large amounts depending on whether the drug is seen } \\
\text { to be safe and effective for treating [respondent's illness]. }\end{array}$ \\
\hline
\end{tabular}

*Each respondent answered questions for all seven scenarios. The scenarios were presented in random order to each respondent and customised to each respondent's self reported diagnosis. 


\begin{tabular}{|c|c|c|}
\hline $\begin{array}{l}\text { Label for type of } \\
\text { question }\end{array}$ & Question and answer choices & Response options \\
\hline Importance question & $\begin{array}{l}\text { How important is it for you to know [the financial } \\
\text { arrangement information] before you consent to } \\
\text { be in this study? }\end{array}$ & $\begin{array}{l}\text { - Extremely important } \\
\text { - Very important } \\
\text { - Somewhat important } \\
\text { - Not very important } \\
\text { - Not at all important }\end{array}$ \\
\hline $\begin{array}{l}\text { Informed consent } \\
\text { requirement question }\end{array}$ & $\begin{array}{l}\text { Do you think that the researcher should be } \\
\text { required to tell you [the financial arrangement } \\
\text { information] before you are asked to participate? }\end{array}$ & $\begin{array}{l}\text { - Yes } \\
\text { - No }\end{array}$ \\
\hline Inclination question & $\begin{array}{l}\text { Which option best reflects how you would feel } \\
\text { about this study, given [the financial arrangement } \\
\text { information]? }\end{array}$ & $\begin{array}{l}\text { - Less inclined to participate } \\
\text { - About the same as before I was } \\
\text { told this information } \\
\text { - More inclined to participate }\end{array}$ \\
\hline Behaviour question & $\begin{array}{l}\text { Which option best reflects what you would do, } \\
\text { given [the financial arrangement information]? }\end{array}$ & $\begin{array}{l}\text { - I would not participate in this study } \\
\text { - I'm not sure } \\
\text { in this study consider participating }\end{array}$ \\
\hline
\end{tabular}

A summary tabulation of the responses to each survey question for each scenario is given in table 4 .

What effect might such conflict of interest information have on the potential research participants? In all scenarios, a minority stated they would be less inclined (range 3\% to $44 \%$ ) to participate or said they would in fact not participate (range $2 \%$ to $32 \%$ ) in a clinical trial because of the conflicts of interest information given in the scenarios. Thus a majority would still consider participating in studies with researcher and institutional financial conflicts of interest. Indeed, for the commercial funding scenario, being told that a drug company is funding the study would make a large minority (41\% to $46 \%$ ) more inclined to participate than if such information had not been disclosed to them.

For the personal income scenario, only a small portion of respondents used the amount of money received by the researcher as a deciding factor in answering their questions (range 7-14\%). Of those respondents, $64-78 \%$ would require informed consent, or be disinclined to participate, or not participate when the line was drawn at greater than $\$ 10000$ (an often mentioned threshold). For example, 10\% of respondents with depression answered that whether researchers should be required to disclose personal income from the drug manufacturer should depend on the amount of personal income. If the threshold is set at "greater than $\$ 10000 ", 78 \%$ of those $10 \%$ would require informed consent.

We further examined the summary descriptive data through multivariate analysis. The results of the repeated measures two-way analysis of variance showed that a scenario effect was present in responses to all four questions. This is summarised in table 5 as rankings of the scenarios in terms of their effects on responses.

An index of overall rankings was created using a simple average rank score for each scenario. The results were:

Table 3 Characteristics of survey respondents and of persons in the Harris Interactive Chronic Illness Database, according to self reported diagnoses

\begin{tabular}{|c|c|c|c|c|c|c|}
\hline & \multicolumn{2}{|c|}{ Heart disease } & \multicolumn{2}{|c|}{ Breast cancer } & \multicolumn{2}{|l|}{ Depression } \\
\hline & $\begin{array}{l}\text { Database } \\
n=15670\end{array}$ & $\begin{array}{l}\text { Respondents } \\
n=2355\end{array}$ & $\begin{array}{l}\text { Database } \\
n=5201\end{array}$ & $\begin{array}{l}\text { Respondents } \\
n=1006\end{array}$ & $\begin{array}{l}\text { Database } \\
n=133716\end{array}$ & $\begin{array}{l}\text { Respondents } \\
\mathrm{n}=2117\end{array}$ \\
\hline Women (\%) & 22 & 19 & 98 & 99.9 & 73 & 60 \\
\hline \multicolumn{7}{|l|}{ Age $(\%)$} \\
\hline $18-29$ & $<1$ & 0 & 1 & $<1$ & 20 & 9 \\
\hline $30-44$ & 7 & 4 & 17 & 14 & 39 & 29 \\
\hline $45-64$ & 67 & $64^{*}$ & 69 & $73^{*}$ & 37 & $55^{*}$ \\
\hline $65+$ & 25 & $31 \dagger$ & 13 & $12+$ & 2 & $8+$ \\
\hline \multicolumn{7}{|l|}{ Education (\%) } \\
\hline $\begin{array}{l}\text { High school } \\
\text { or less }\end{array}$ & 21 & 17 & 20 & 20 & 20 & 18 \\
\hline Some college & 40 & 37 & 40 & 40 & 45 & 42 \\
\hline College & 21 & 20 & 23 & 20 & 22 & 22 \\
\hline Post-college & 17 & 25 & 17 & 21 & 13 & 18 \\
\hline \multicolumn{7}{|l|}{ Income (\%) } \\
\hline$<25 \mathrm{~K}$ & 15 & 19 & 13 & 20 & 23 & 24 \\
\hline 25 to $<50$ & 33 & 26 & 34 & 18 & 36 & 27 \\
\hline $50 \mathrm{~K}$ to $<100 \mathrm{~K}$ & 31 & 29 & 30 & 31 & 27 & 28 \\
\hline$>100 k$ & 10 & 12 & 8 & 12 & 6 & 9 \\
\hline No answer & 11 & 13 & 14 & 19 & 8 & 12 \\
\hline \multicolumn{7}{|l|}{ Race $(\%)$} \\
\hline White & 93 & 93 & 91 & 93 & 88 & 91 \\
\hline Black/African & 1 & 1 & 3 & 2 & 3 & 2 \\
\hline \multicolumn{7}{|l|}{ American } \\
\hline Hispanic & 1 & 1 & 1 & 1 & 3 & 2 \\
\hline Other & 3 & 3 & 4 & 3 & 4 & 4 \\
\hline
\end{tabular}




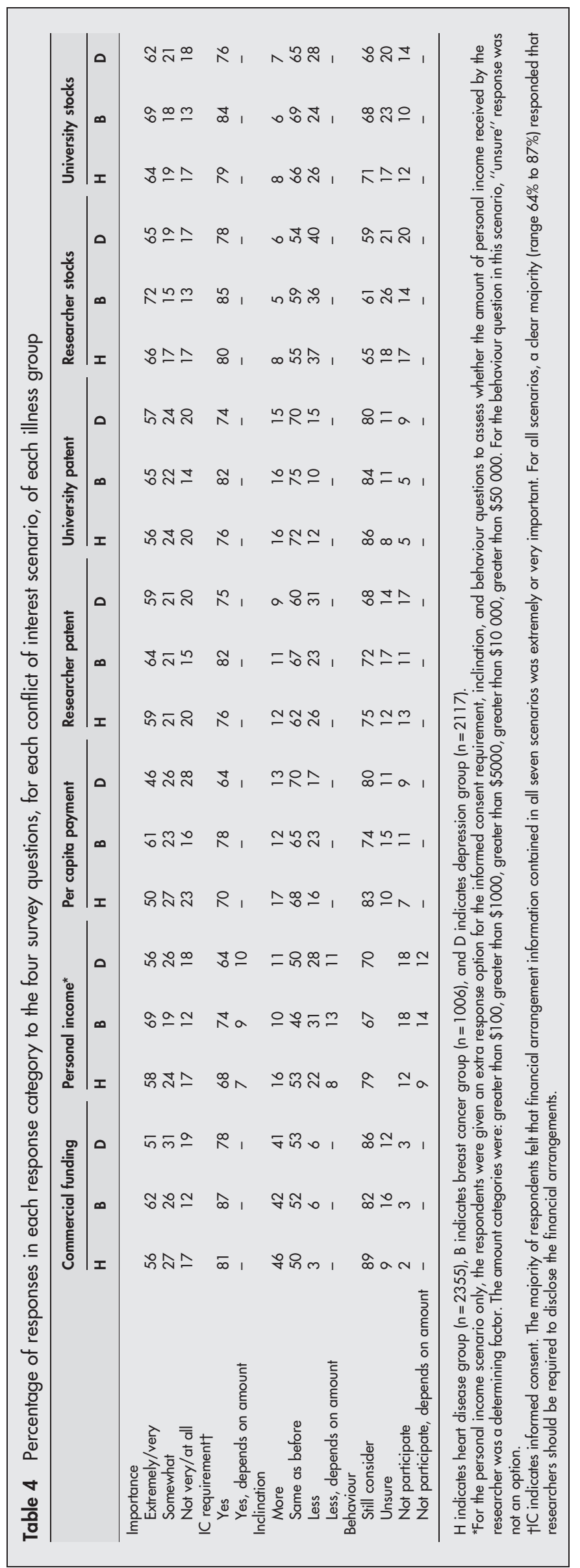




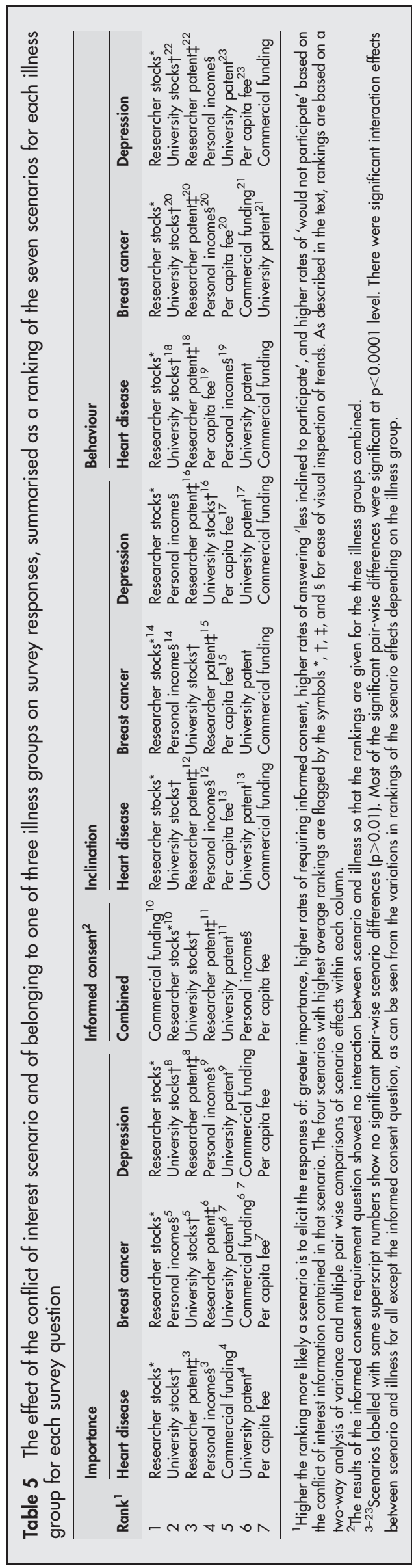

researcher stocks 1.2, university stocks 2.8 , researcher patent 3.7, personal income 4.0, per capita payments 5.3, university patent 5.3, and commercial funding 5.8. (The top four scenarios are flagged by the symbols *, $\dagger, \ddagger$, and $\S$ in table 5.) Thus, with the exception of the university stock ownership scenario, the three scenarios depicting personal financial incentives for the individual researcher tended to elicit the highest importance and greatest negative (that is, feel disinclined to participate, or would not participate) responses.

In terms of the effect of demographic and illness factors, because of the high number of regression models (seven scenarios with four questions each, resulting in 28 models), only a summary of the results are described here. The most consistent and significant effects on responses were found for education and illness variables: the more educated persons valued information more but also were less willing to participate; breast cancer group valued information more relative to the other illness groups but also was more willing to participate. Income, sex, age, race, and ethnicity had an inconsistent or little effect. Most of the statistically significant odds ratios fell between 0.5 and 2.0 (data not shown) and usually even smaller in magnitude. Given that odds ratios for relatively common events can exaggerate effect sizes,$^{29}$ the overall effects of demographic and illness category factors were thus modest and did not change the overall trend of responses discussed above.

\section{DISCUSSION}

While the perspective of research subjects is becoming an increasing focus of research, ${ }^{30}{ }^{31}$ little is known about their attitudes and potential behavioural responses to researcher and institutional conflicts of interest. Aside from one anecdotal account by an industry executive, ${ }^{32}$ we found one survey of 200 medical outpatients regarding their attitudes toward financial incentives of doctors in Phase IV postmarketing research whose findings are generally consistent with our results. Our study examined a wider variety of scenarios and, more importantly, surveyed people who actually had illnesses of interest and were interested in participating in research. Further, we measured not only attitudes but also potential behavioural consequences of disclosing conflict of interest information.

\section{Implications of study findings}

The main, robust finding of our study is a dual trend: (1) most potential research participants desire to be informed (and believe this should be required) regarding financial conflicts of information in research even while (2) still wanting to participate in such research. The potential research participants' desire and demand to know such information is unlikely to be based upon a pre-existing distrust of research: this group consisted of only those already willing to participate in research. Indeed, a clear majority would still consider participating in clinical trials with even the most controversial conflict of interest present (researcher's substantial equity interest in the company whose product is being studied). Instead, in our study the potential research participants' responses echo past studies on patient preferences for autonomy in medical decision making. Those studies found that patients value being informed even if they are willing to defer decisions to their physicians. ${ }^{33}$

Thus the presumption by some that a disclosure of financial arrangements by its very existence casts suspicion on the party with the conflict of interest was not borne out. ${ }^{8}$ In an unexpected finding, nearly half of the respondents said they were more inclined to participate in a clinical trial if they knew that "the drug company whose product is being studied 
is funding the study." While the analysis of the open ended comments provided by our respondents is not yet complete, a common answer among those more inclined to participate was the respondent's desire to assess the company's reputation. As one respondent put it, "I would feel better about it if it was a well known company funding the project."

However, a sizable minority would not participate in research that has certain conflicts of interest present, namely, if the researcher owns substantial equity stake in the sponsoring company or if the researcher earns personal income from the sponsor. (It is interesting to note that while the current federal regulations ${ }^{7}$ and, consequently, policy debates emphasise amount thresholds, only a small minority of our respondents conditioned their responses upon the amounts involved.)

Given these findings, it is difficult to defend the practice of non-disclosure: if one knows that a sizable number, were they informed, would not wish to participate, then it may be unethical not to inform them of those facts in the absence of strong countervailing reasons. ${ }^{18}$

The presence of significant scenario effects is an important finding. The pattern of responses suggests that the respondents were more wary of individual investigators' conflicts of interest than of institutional ones. However, this does not mean that the respondents did not see institutional conflicts as a problem: the university stocks scenario ranked second in raising concerns from the respondents. Further, the most problematic conflict of interest situation-that is, an investigator owning substantial equity stake in a company whose product is being tested-evoked the greatest wariness from the respondents. This may simply confirm the fact that financial arrangement information is not technical, scientific detail that may confuse the potential research participants-a rationale sometimes cited against a policy of disclosure. ${ }^{34}$ Instead, such information may be comprehensible by most people and may form an important basis for expressing their values by agreeing or disagreeing to participate in some research. For instance, we found that most who say they would decline to participate, not unexpectedly cited potential for bias and concern about safety as their reasons. However, those who felt more inclined to participate gave coherent reasons as well. For instance, for the researcher patent ownership scenario, some focused on the presumed expertise of a patent owner ("I would be getting the benefit of first hand knowledge from the researcher.")

Illness type and education had significant and consistent, if modest, effects on response patterns. These are findings that need further study and may have implications for designing contextually sensitive informed consent procedures. We note that although some sociodemographic and illness variables had statistically significant effects, the effect sizes were relatively small in comparison with the robust main trend of persons placing high value on the conflict of interest information and yet who were willing to participate in such research.

\section{Limitations}

There are limitations to this study. Firstly, it is inherently difficult to operationalise the concept of a "potential research participant" since all clinical trials rely on self selected patient volunteers. Despite this difficulty, given the important yet neglected ethical voice of such persons, we chose to use two necessary, but admittedly not exhaustive, criteria to define a potential research participant. To the extent that the self selection qualities of our sample recapitulate those of actual research participants, the results of this study convey the values of a population of legitimate stakeholders in the financial conflicts of interest debate.
Secondly, the overall response rate was relatively low. It should be noted, however, that the respondent group reflected the sociodemographic features of the entire database. Further, because of the large sample size, we were able to perform meaningful multivariate analyses to show that the main findings are quite robust, even after accounting for several potential confounding factors.

Finally, there are potential limitations in the use of the internet for survey research. Despite the precautions taken in our procedures, the "digital divide" might make the sample frame itself unrepresentative of potential research participants. Around the time of this survey, 56\% to $59 \%$ of all Americans were on the internet. ${ }^{35}$ Thirty eight per cent of those earning under $\$ 30000,37 \%$ of those with high school education or less, $43 \%$ of blacks, and $47 \%$ of Hispanics were using the internet. ${ }^{35}$ The lower than expected number of minority respondents in this study reflects the lower than expected number of minorities in the Harris Interactive Chronic Illness Database and may reflect their unwillingness to be part of such a database. Because the use of the internet for research is relatively new, we do not yet know whether there is an uncorrectable bias due to the fact that Americans using the internet-especially those willing to be part of a health survey database-are fundamentally different from the non-users, in ways unaccounted for by education, income, sex, race/ethnicity, and age. We note again, however, that although our responding group was overwhelmingly white, the large number of respondents contained enough persons from a wide range of sociodemographic (including racial and ethnic) backgrounds to conduct meaningful multivariate analyses.

\section{CONCLUSIONS}

The current debate over financial conflicts of interest in clinical research focuses on institutional policies and on individual researchers' conflicts of interest. It is unclear whether disclosure, management, or elimination of conflicts of interest is the best solution. Our study should not be taken to mean that only disclosure is required. It supports disclosure but it did not examine the further issues on management or elimination of conflict directly. It is probably wise to interpret the apparent willingness of potential research participants to tolerate substantial conflicts of interest to mean that it is not too late to make the financial aspects of clinical research more transparent to all.

This study provides a clear answer to the question of whether or not potential research participants want to know the financial conflicts of interest of researchers and institutions. ${ }^{34}$ They clearly and overwhelmingly do. Our respondents were also able to make distinctions between the different types of conflicts of interest. Financial conflict of interest is not a technical or complex concept understandable only by researchers and their institutions. Concern over financial conflicts of interest requires not so much an intimate knowledge about science as some intuitive grasp of ordinary human behaviour.

We cannot tell from this study whether the current high level of trust in researchers and their institutions will continue as more stories of alleged adverse outcomes related to financial conflicts of interest arise. ${ }^{24}$ However, it appears that the current practice of non-disclosure of worrisome conflicts of interest do not conform to the values and wishes of potential patient volunteers without whose participation no research can occur.

\section{ACKNOWLEDGEMENTS}

We thank Jason Karlawish, MD for a critical review of the manuscript, Cynthia Dunn, MD for critical review of the survey questionnaire and of the manuscript, and Gary Chadwick, PharmD 
and David Orentlicher, MD, JD for critical review of the survey questionnaire.

\section{Authors' affiliations}

S Y H Kim, E D Caine, Department of Psychiatry, University of Rochester Medical Center, Rochester NY, USA

C Cox, Biometry and Mathematical Statistics Branch, National Institute of Child Health and Human Development, Bethseda MD, USA

R W Millard, P Nisbet, HarrisInteractive, Inc, Rochester, NY, USA

This study was in part supported by NIMH grant MH-18911, an American Association for Geriatric Psychiatry Eisai-Pfizer Alzheimer's Disease Research Fellowship, and the Rivas Endowment of the Department of Psychiatry, University of Rochester.

\section{REFERENCES}

1 Drazen J, Koski G. To protect those who serve. N Engl J Med 2000;343:1643-5.

2 Lo B, Wolfe L, Berkeley A. Conflict-of-interest policies for investigators in clinical trials. N Engl J Med 2000;343:1616-20.

3 World Medical Association. Declaration of Helsinki. JAMA 1997;277:925-6.

4 Van McCrary S Anderson C, Jakovljevic J, et al. A national survey of policies on disclosure of conflicts of interest in biomedical research. N Engl J Med 2000;343:1621-6.

5 Blumenthal D, Campbell EG, Causino N, et al. Participation of life-science faculty in research relationships with industry. $N$ Engl J Med $1996 \cdot 335: 1734-9$

6 Bodenheimer T. An uneasy alliance-clinical investigators and the pharmaceutical industry. N Engl J Med 2000;342:1539-44.

7 NIH. Objectivity in research. NIH Guide, volume 24, number 25. 14 July, 1995.

8 Rothman KJ. Conflict of interest. The new McCarthyism in science. JAMA 1993;269:2782-4.

9 Krimsky S, Rothenberg LS. Financial interest and its disclosure in scientific publications. JAMA 1998;280:225-6.

10 Davidoff F, DeAngelis CD, Drazen J, et al. Sponsorship, authorship, and accountability. N Engl J Med 2001;345:825-7.

11 Emanuel EJ, Steiner D. Institutional conflict of interest. N Engl J Med 1995;332:262-7

12 Korn D. Conflict of interest: a university perspective. In: Cheney D, ed. Ethical issues in research. Frederick, MD: University Publishing Group, 1993: 113-25.

13 Martin J, Kasper D. In whose best interest? Breaching the academic-industrial wall. N Engl J Med 2000;343:1646-9.

14 Angell M. Is academic medicine for sale? N Engl J Med 2000;342:1516-18.

15 Press E, Washburn J. The kept university. Atl Mon 2000:39-54.
16 Blumenthal D, Causino N, Campbell E, et al. Seashore: relationships between academic institutions and industry in the life sciences-an industry survey $N$ Engl J Med 1996;334:368-73.

17 La Puma J, Stocking CB, Rhoades WD, et al. Financial ties as part of informed consent to postmarketing research: attitudes of American doctors and patients. BMJ 1995;310:1660-3.

18 Wilkinson T. Research, informed consent, and the limits of disclosure. Bioethics 2001; 15:341-63.

19 Huth E. Conflicts of interest in industry-funded clinical research. In: Spece RG Jr, Shimm DS, Buchanan A, eds. Conflicts of interest in clinical practice and research. New York: Oxford University Press, 1996:389-406.

20 Shimm DS, Spece RG. Industry reimbursement for entering patients into clinical trials: legal and ethical issues. Ann Intern Med 1991;115:148-51.

21 Lind SE. Fee for service research. N Engl J Med 1986:314:312-15.

22 Blumenthal D, Gluck M, Louis KS, et al. University-industry research relationships in biotechnology: implications for the university. Science 1986;232:1361-6.

23 Cho M, Shohara R, Schissel, et al. Policies on faculty conflicts of interest at US universities. JAMA 2000;284:2203-8.

24 Wilson D, Heath D. Uninformed consent. The Seattle Times, Reprinted from 11-15 March, 2001

25 Neaves WB, Wildenthal K. Conflict-of-interest issues surrounding faculty participation in, and ownership of, technology and drug companies. In: Cheney D, ed. Ethical issues in research. Frederick, MD: University Publishing Group, 1993:139-45.

26 Moses H, Martin J. Academic relationships with industry. JAMA 2001;285:933-5.

27 Diggle PJ, Liang KY, Zeger SL. Analysis of longitudinal data. Oxford: Clarendon Press, 1994.

28 McCullagh P, Nelder JA. Generalized linear models. London: Chapman and Hall, 1989.

29 Zhang J, Yu K. What's the relative risk? A method of correcting the odds ratio in cohort studies of common outcomes. JAMA 1998;280:1690-1.

30 Edwards SJL, Lilford RJ, Hewison J. The ethics of randomised controlled trials from the perspectives of patients, the public, and healthcare professionals. BMJ 1998:317:1209-12.

31 Karlawish JH, Lantos J. Community equipoise and the architecture of clinical research. Camb Q Healthc Ethics 1997;6:385-96.

32 Finkel MJ. Should informed consent include information on how research is funded? IRB 1991;13:1-3.

33 Ende J, Kazis L, Ash A, et al. Measuring patients' desire for autonomy: decision making and information-seeking preferences among medical patients. J Gen Intern Med 1989;4:23-30.

34 Jellinek MS, Levine RJ. IRBs and pharmaceutical company funding of research [article and commentary]. IRB 1982;4:9-10.

35 Rainie L, Packel D. More online, doing more: 16 million newcomers gain internet access in the last half of 2000 as women, minorities, and families with modest incomes continue to surge online. Washington DC, The Pew Internet \& American Life Project, 2001. http://www.pewinternet.org/reports/ toc. asp? Report $=30$. 